\title{
Who's afraid of Perfectionist Moral Enhancement? A Reply to Sparrow
}

\author{
Pei-hua Huang
}

\begin{abstract}
Robert Sparrow recently argues that state-driven moral bioenhancement is morally problematic because it inevitably invites moral perfectionism. While sharing Sparrow's worry about state-driven moral bioenhancement, I argue that his anti-perfectionism argument is too strong to offer useful normative guidance. That is, if we reject state-driven moral bioenhancement because it cannot remain neutral between different conceptions of the good, we might have to conclude that all forms of moral enhancement program ought not be made compulsory, including the least controversial and most popular state-driven program: compulsory (moral) education.

In this paper, I argue that instead, the spirit of Sparrow's worry should be recast in the language of the capability approach - an approach that strives to enhance people's capabilities to develop their own conceptions of the good by restricting itself from endorsing thick conceptions of the good. The distinction made regarding thick and thin conceptions of the good helps better capture sentiments against state-driven bioenhancement programs without falling prey to the issues I raise against Sparrow's anti-perfectionist arguments.
\end{abstract}

\section{Keywords}

Moral Perfectionism, Moral Enhancement, Capability Approach, Revisibility

\section{Introduction}

Robert Sparrow $^{1}$ recently argues that state-driven moral bioenhancement is morally problematic because it inevitably invites moral perfectionism. Sparrow argues that even though advocates of state-driven moral bioenhancement have tried to refrain themselves from making

\footnotetext{
${ }^{1}$ Sparrow, R. (2014a). Egalitarianism and moral bioenhancement. American Journal of Bioethics, 14(4), 20-28; Sparrow, R. (2014b). Better living through chemistry? A reply to Savulescu and Persson on 'moral enhancement'. Journal of Applied Philosophy, 31(1), 23-32
} 
substantive claims about the nature of morality, the design of bioenhancement programs nevertheless will not be able to remain neutral between different conceptions of morality. ${ }^{2}$ This is deeply problematic from Sparrow's point of view because our conception of morality is a vital source for us to conceive our own moral ideals and understand who we are; allowing the state to impose moral bioenhancement onto us is allowing the state to shape us into someone whom we might not aspire to become. Call this anti-perfectionism argument.

While sharing Sparrow's worry about state-driven moral bioenhancement, I argue that his anti-perfectionism argument is too strong to offer useful normative guidance. I argue that if we reject state-driven moral bioenhancement because it cannot remain neutral between different conceptions of the good, we might have to conclude that all forms of moral enhancement program ought not be made compulsory, including the least controversial and most popular state-driven program: compulsory (moral) education. I argue that instead, the spirit of Sparrow's worry should be recast in the language of the capability approach - an approach that strives to enhance people's capabilities to develop their own conceptions of the good by restricting itself from endorsing thick conceptions of the good. ${ }^{3}$ The distinction made regarding thick and thin conceptions of the good helps us clarify why most of us share the intuition that well-designed education programs can be applied in a compulsory manner while being reluctant to embrace those loaded with problematic ideologies. I argue that by using this distinction, we may better capture sentiments against state-driven bioenhancement programs without falling prey to the issues I raise against Sparrow's anti-perfectionist arguments.

\footnotetext{
2 Sparrow 2014a op cit. note 1, pp. 22-23

3 Sen, A. (2001). Development as freedom. Oxford: Oxford University Press; Nussbaum, M. (1999). Sex and justice New York: Oxford University Press.
} 


\section{Clarification: State-Driven Moral Bioenhancement and the Worry}

Before I explain why Sparrow's anti-perfectionism argument is too strong to be applicable, I shall give a brief introduction to the sort of state-driven moral bioenhancement that concerns Sparrow. Briefly, the idea of state-driven moral bioenhancement comes from Ingmar Persson and Julian Savulescu's 2012 monograph, Unfit for the Future ${ }^{4}$, where they argue that governments around the world ought to dedicate more resources to researching and designing moral bioenhancement solutions to address urgent issues such as climate change and global terrorism.

Many reasons motivate Persson and Savulescu to make this proposal. But we can safely sum them up into the following two points: First, more and more studies from psychology and neuroscience suggest that our moral shortcomings are linked to our neurological wiring. As a result, potentially, we could increase people's willingness to take part in initiatives against climate change and global terrorism by directly modulating our existing neurological wiring via biomedical means. ${ }^{5}$ Second, existing measures such as education seem to be very ineffective at making a real change in people's moral behaviours - people might know they ought to change their way of living to help reduce carbon emission but still fail to act in accordance with their moral convictions. This discrepancy between moral knowledge and moral behaviour suggests that there's an urgent need to design new means to directly modulate people's moral motivations - we must act quickly, once the temperature hits the 2 degrees Celsius limits, there's no going back. Owing to these two major reasons, Persson and Savulescu argue that should a safe and effective means for moral bioenhancement be found, governments around the world should seriously consider imposing moral bioenhancement on all citizens.

\footnotetext{
${ }^{4}$ Persson, I., \& Savulescu, J. (2012). Unfit for the future: The need for moral enhancement. Oxford: Oxford University Press.

${ }^{5}$ However, it is important to note that findings that support this idea are still preliminary and require further investigation. For instance, whether oxytocin can make people to be more willing to trust others is still unclear. See, for example, Nave, G., Camerer, C., \& McCullough, M. (2015). Does oxytocin increase trust in humans? A critical review of research. Perspectives on Psychological Science, 10(6), 772-789.
} 
While this proposal is well-intended, some of the assumptions it needs to make are controversial:

$[\mathrm{T}]$ he project of moral bioenhancement implies that those people directing it know what being more moral consists in. Despite the best efforts of its advocates to make only the most minimal claims about the benefits of altruism, a sense of justice, and the absence of distorting emotions or cognitive biases, such as racism, any actual program of enhancement would inevitably require taking a position on controversial questions about the relative importance of each of these and the desirability of different combinations of dispositions. Thus, any state that embarked upon moral bioenhancement would thereby be committed to moral perfectionism. (Sparrow 2014a, p. 29)

Sparrow's point here is simple - for any state to initiate a compulsory moral bioenhancement program, the state must first hire a group of 'moral experts' to design the program. But who are these moral experts to tell us what a morally superior person looks like? Sparrow argues that even if we may unanimously agree that certain behaviours are morally appalling, this consensus is insufficient to ensure an agreement on a conception of the good. Nor is it sufficient to ensure an agreement on how to pursue or realise this conception of the good. For instance, we may all agree that rape, torture, and murder are morally concerning, and hence find it less worrisome for the government to try using biotechnologies to eradicate them. ${ }^{6}$ However, when it comes to conceptions of the good, people often hold different views - some may believe that

\footnotetext{
${ }^{6}$ Sparrow 2014b op cit. note 1, p. 22. However, it is worth noting that even measures that aim to deal with the evilness in the world would still spark heated debates. Chemical castration is one of the examples. Although some countries allow serial sex offenders to voluntarily choose to undergo chemical castration to shorten the length of imprisonment, this sort of policy still can be viewed as coercive and harmful to the prisoner's right to bodily integrity. See Shaw, E (2019). 'The Right to Bodily Integrity and the Rehabilitation of Offenders through Medical Interventions: A Reply to Thomas Douglas', Neuroethics, 12(1), 97-106.
} 
equality is more important than other values, while others believe the importance of liberty outweighs equality.

Disagreements like this may further entangle with other disagreements, e.g. what sort of person would be considered a virtuous person, and what sort of interpersonal relations would constitute obligation. In other words, the disagreement is not merely a factual disagreement, it is also a disagreement about fundamental moral commitments, and thus about people's identity. ${ }^{7}$ Trying to use moral bioenhancement to alter people's behaviour in such domains may therefore seriously damage their identity.

Sparrow's anti-perfectionism argument, therefore, can be summed up as follows: We should reject the proposal for state-driven moral bioenhancement because this proposal presumes that it is permissible for a state to hire a group of moral experts to shape its people's characters into ones those receiving enhancement might not identify with. ${ }^{8}$ In such a society, people's conceptions of the good are not viewed as equally valuable. Instead, they are treated like pawns that reach the end of a chessboard: despite all the possibilities of what they could be, what they should turn into is decided by the experts.

\section{Our Perfectionist Moral Education}

Sparrow's anti-perfectionism argument, however, is too strong. This argument does not only challenge the moral permissibility of state-driven moral bioenhancement. Once we take a closer look at the implications of the argument, we will find that this argument also undermines the permissibility of the least controversial form of moral enhancement, one that is explicitly endorsed by Sparrow: moral education. ${ }^{9}$

\footnotetext{
ibid: 23.

8 ibid: 26.

9 ibid and Sparrow 2014a, op cit. note 1.
} 
When we talk about moral education, or education in general, what comes to mind is a picture where the educator tries to guide their students to think independently and to help their students to find their own voices. It's vastly different from using biochemicals to instil a particular conception of the good. However, if Sparrow's main concern is moral perfectionism, moral education (even the very idealistic version described above) fares no better than statedriven moral bioenhancement. For instance, in their discussion of indoctrination anxiety, Joshua DiPaolo and Robert Simpson argue that some commonly adopted educational practices are not reason-engaging. When 'teaching' very young children, strategies adopted by adults are often entirely non-rational; some are even closer to 'conditioning'. ${ }^{10}$ We often see adults giving young children sweets or praise when they perform a behaviour we would want them to cultivate, inculcating positive feelings for the target behaviour. Sometimes, we also use this strategy to encourage young children to adopt the moral beliefs we want them to internalise, such as honesty, altruism, and kindness. In other words, when we take a closer examination on early education, we will discover that perfectionist practice is widely practiced and welcome .

Some may argue that the example of educating very young children is not convincing because very young children are not mature enough to have their own conceptions of the good, and are not capable of conducting independent thinking to make autonomous decisions. Hence they might say it's therefore problematic to say that making decisions on their behalf is deeply perfectionist. It is also imaginable that some may insist that the parent-child relationship is different from the relationship between a state and its people, and therefore it is wrong to compare the two in this way. I agree with the point that educating very young children is very different from other forms of education and also that parent-child relationship is special, but I don't think these complaints can rescue education from the perfectionism complaint.

10 DiPaolo, J., \& Simpson, R. M. (2015). Indoctrination anxiety and the etiology of belief. Synthese, 193(10), 3079-3039. 
Recall the idealised picture of moral education I described in the beginning of this section - an education that aims to guide students to think independently and to help the students to find their own voices. Living in a liberal democratic society sometimes blinds us to the fact that not every form of education is like this. Education can become a tool for instilling problematic ideologies and oppressive social norms, and it is not rare to see education used for these purposes.

Of course, we can make a distinction here and argue that this certain 'education' should be labelled 'brainwashing' and should not be allowed in a liberal democratic society. For instance, Sparrow argues that ideal moral education should be run in a manner where the educator treats the educated as their moral equals; educators who fail to do this are not genuine educators. ${ }^{11}$ This is a good and useful distinction. I agree that a good education should aim to help people discover their potentials and cultivate an ability to think independently. However, prioritising values like autonomy is also value-laden. Sparrow and I could still be questioned, 'Who are you to decide which values should be the fundamental values embedded in education?' The problem of moral perfectionism resurfaces.

I am by no mean suggesting here that we should abolish all forms of moral education. Rather, my point is that if we think certain moral enhancement programs (regardless of the means by which they are implemented) should not be made compulsory is due to their commitment to 'moral perfectionism', we will have to conclude that every proposal for compulsory moral enhancement is equally problematic on this ground. Designing moral education based on liberal ideals such as autonomy still commits one to certain perfectionist values. Sparrow's anti-perfectionist argument is therefore too strong to help us clarify why many philosophers

11 Sparrow 2014a op cit. note 1, p. 26. 
(and laypeople) believe there are fundamental differences between genuine moral education and other more controversial moral enhancements such as moral bioenhancement. ${ }^{12}$

\section{Capturing the Worry with an Alternative: The Capability Approach}

Despite the challenges I raise against the anti-perfectionism argument, I do agree with Sparrow's general concerns about state-driven moral bioenhancement. What distinguishes my position and Sparrow's is how to capture the worries about state-driven moral bioenhancement.

To begin with, one of Sparrow's major concerns is that Persson and Savulescu's proposal might commit to a certain form of moral perfectionism that is at odds with the enhancement recipient's personal commitments. This may then create a moral inequality because the enhancement recipient's moral worldview would not be fully respected by those who design the enhancement program. If I understand Sparrow's concern correctly, then moral perfectionism per se is not the real issue here. Rather, the real issue is the threat to moral equality and the disrespect to value pluralism. Once the anti-perfectionist argument is understood in this way, the task will be explaining why the type of moral perfectionism committed by genuine moral education is generally non-oppressive and also respectful to value pluralism, whereas the type of moral perfectionism committed by Persson and Savulescu's proposal is not.

The capability approach provides great insight to help us clarify what's at stake here. ${ }^{13}$ In fact, what motivates early capability scholars to develop this approach has much overlap with those issues that concern Sparrow the most. The capability approach was first articulated as an approach to deal with global injustice and poverty, issues that are extremely difficult to address both because of the scale of the problem and also because of the huge diversity in

\footnotetext{
12 However, whether means that involves biochemicals is always more controversial is debatable. For more discussion on why the dichotomy between biomedical and non-biomedical means might not always hold the water, see Huang, P.-H. (2015). Authenticity, autonomy and enhancement. Dilemata, 19, 39-52; Huang, P.-H. (2018). Moral enhancement, self-governance, and resistance. Journal of Medicine and Philosophy, 43(5), 547-567.

13 Sen, op cit. note 3; Nussbaum, op cit. note 3.
} 
human practice and culture. This diversity makes it difficult for scholars to confidently argue that an apparently unjust practice of a foreign culture is truly unjust - it might turn out that the practice is only unjust when viewed through the lens of Western 'ideology'. What makes this task even more difficult is that many of the oppressed might not be aware of their oppression - they might have adjusted their expectations regarding their lives so as to rationalise their suffering. However, should we refrain from examining injustices happening in other parts of the world due to a worry about cultural imperialism, we might end up allowing those injustices to persist and suffering to continue.

Recognising these problems, the capability scholars, most notably Martha Nussbaum and Amartya Sen, decided to address global injustice by asking a different question: what are the most essential capabilities without which human flourishing would be difficult, if not impossible? The insight behind this approach is that while we may all have different views on what a good life consists in, there is nevertheless a set of fundamental human capacities serving as the foundation for the development and pursuit of all sorts of views on human flourishing.

Take the capability for bodily integrity and health for instance. It would be difficult for an Indian widow to tell if her health condition was poor during the Great Bengal Famine, should her needs for bodily integrity and health are constantly denied. Indeed, cccording to the figure provided by Sen, despite being severely affected by the Great Bengal Famine of 1943, only 2.5 percent of affected Indian widows reported that they believed they were ill or in indifferent health, whereas 48.5 percent of affected Indian widowers complained about their health conditions. ${ }^{14}$ The mismatch between reports from widows and widowers shows that people who live in an oppressive society could internalise unjust norms and lose the ability to challenge or question those norms - while oppressive norms do not destroy all the instrumental reasoning

${ }^{14}$ Sen, A. (1985). Rights and capabilities In T. Honderich (Ed.), Morality and objectivity. London: Routledge. 
of the oppressed, the sanity that could otherwise help these oppressed people identify the wrongfulness of their culture's norms is severely damaged. ${ }^{15}$

In other words, while arguing that bodily integrity and health should be protected commits one to a certain moral worldview, the moral perfectionism it entails is a very special one - one where each and every individual member of the society can have his or her own conception of the good. The fact that this form of moral perfectionism tries to make sure that all will possess essential capabilities to pursue their own conceptions of the good demonstrates a strong commitment to treating all as moral equals. It is in this way, Sen and Nussbaum assure us that their investigation into global injustice commits no cultural imperialism.

One thing worth clarifying is that this approach does not require that people must use their capabilities to bring about certain human functionings. If this were the case, then enforcement of the capability approach would lean toward totalitarian interventions and might seriously invade people's right to self-determination, another important but rather abstract capability. Rather, enforcement should be to ensure that people can decide how (and whether) to use important capabilities, such as the capability for bodily integrity, health, physical survival, and practical reason, to pursue their own life plans. ${ }^{16}$ To have the capability for bodily health, for example, is to be able to either enjoy good health, or to sacrifice that health, for example, by joining a hunger strike. The example of suffragettes who went on hunger strikes but were

\footnotetext{
${ }^{15}$ However, it is not to say that people living under this sort of condition will never be able to develop their conception of the good. The fact that there were still 2.5 percent of affected Indian widows capable of reporting their being ill shows that some could still overcome this sort of adverse situation and articulate their views. I thank the anonymous referee of the journal for raising this point to me. Cf. Nussbaum, M. (1997). Capabilities and human rights. Fordham Law Review, 66(2), 273-300 and Wolf, S. (1987). Sanity and the metaphysics of responsibility. In F. Schoeman (Ed.), Responsibility, character, and the emotions: New essays in moral psychology (pp. 42-62). Cambridge: Cambridge University Press.
}

\footnotetext{
16 However, which capability should be regarded as important or essential capability is itself debatable. Nussbaum thinks that there's a universal list of essential capabilities that all need to have in order to enjoy human flourishing, yet Sen explicitly refuses to defend 'one pre-determined canonical list of capabilities, chosen by theorists without any general social discussion or public reasoning'. I thank the anonymous referee of the journal for pushing me clarifying this point. For more discussion, see Nussbaum, op cit. note 3; Sen, A. (2005). Human rights and capabilities. Journal of Human Development, 6(2), 151-166.
} 
force-fed by the government demonstrates how the capability to have health is not just about enjoying a healthy life. This is also reveals why despite both resulted in physical frailty, Gandhi's hunger strike and the suffering of a widow during the Great Famine in 1943 should be understood in different ways. The former had the capability to choose whether or not to eat enough to be healthy, the latter had no choice but to have low human functioning due to malnutrition. ${ }^{17}$

\section{Thin and Thick Conceptions of the Good}

Applying the capability approach to addressing the issues I highlighted in the previous section, I argue that while it is impossible for us to avoid committing to some form of moral perfectionism, we nevertheless can and should try to make our perfectionism commitment as thin as possible.

Not all conceptions of the good are born the same. Some assume more than others. The more assumptions a conception of the good makes, the thicker the conception becomes. This subsequently influences how open a conception of the good can be to working together with other conceptions of the good. Take the Confucian conception of the good as an example. One major assumption it makes regarding interpersonal relationships - filial piety (xiao) - rules out the possibility of it remaining open to many conceptions of the good from Western society. According to the teachings of Confucius, harmonious family relationships comprise a key part of the ideal good life, and to achieve this ideal, one should obey parents, even if that means not doing what one believes is the morally right thing to do. ${ }^{18}$ This teaching is deeply at odds with the conception of ideal interpersonal relationships many people now endorse - even the

\footnotetext{
17 Sen 2005 op cit. note 16.

18 In Confucius' Analects, it is recorded that Confucius believes that 'in serving your father and mother you ought to dissuade them from doing wrong in the gentlest way. If you see your advice being ignored, you should not become disobedient but should remain reverent. You should not complain even if in so doing you wear yourself out.' See Confucius. (1979). The analects (D. C. Lau, Trans.). New York: Penguin Books.
} 
younger generation raised in countries influenced by Confucian culture disagree with this conception.

This example shows that while having meaningful interpersonal relationships is widely considered one of the most essential human capabilities, Confucian filial piety as a type of interpersonal relationship goes beyond this essential human capability. This is because Confucian filial piety not only endorses the importance of interpersonal relationships, it also endorses a specific notion of good that might not be endorsed by people who do not follow Confucian teachings.

In other words, once a person adopts such a conception of the good, their conception of the good cannot consistently endorse those conceptions of the good that prioritise justice and truth above 'harmonious family relationships'. Thus in this sense, the Confucian conception of the good is a relatively thick conception.

Arguing that the Confucian conception of the good is a relatively thick conception of the good is not to suggest that this conception of the good is inferior. Rather, what I intend to argue with this example is merely that there are other incompatible conceptions of the good that can lead to a meaningful life and that life-affirming interpersonal relationships can be reached and maintained in forms that do not endorse filial piety. Should we build up a moral enhancement program based on this sort of thick conception of the good and impose this enhancement on others, we may risk sending the message that other conceptions of the good, say, the Christian conception of the good, are not worth pursuing. Worse, we may end up becoming oppressors, forcing our views on others. Thus, when thinking about moral enhancement, we should endorse only the thinnest possible conception of the good - in this example, one compatible at least with both Confucian and Christian interpersonal relationship values.

Similar idea could be found in Thomas Nagel's defence of liberalism. Nagel acknowledges that 'liberal values' such as paying respect to value pluralism embedded in liberal 
democratic society may suggest that liberal democratic society does not take a neutral stance regarding all values (e.g. supporting the freedom of religion instead of supporting Christian values), yet he maintains that 'bias' towards the liberal values does not cause oppression or coercion as a bias towards many of the non-liberal values has done in human history. This is because the core consideration for liberal democracy is to make sure that all members of a society will not be treated as mere means, but always as ends. As a result, while this principle indeed precludes the moral permissibility of a state imposing many conceptions of the good on its members, it does not entail that the state should never endorse any values. So long as the conception of the good endorsed by the state could be enjoyed by all members of the society regardless of their conception of the good, endorsing these 'impersonal goods' will not contradict the core consideration of liberalism. ${ }^{19}$ According to this view, the political structure supported by liberal democrats could be vindicated by showing the structure to be 'impersonal'. This is because the central concern for the liberal is to have a political structure that can respect all as moral equals. ${ }^{20}$

\section{Measuring The Thickness of Moral Bioenhancement}

I now turn to addressing why, viewed through the lens of the capability approach, the conception of the good underlying Persson and Savulescu's proposal is not thin enough to be justified under the capability approach.

Indeed, in Unfit, Persson and Savulescu have already noticed concerns that are highly similar to those expressed by Sparrow and tried to address these issues. Persson and Savulescu recognise that some of their views on issues such as moral responsibility and moral rights may be philosophically controversial and that designing a compulsory moral bioenhancement

\footnotetext{
19 Nagel, T. (1991). Equality and partiality. Oxford: Oxford University Press, pp. 159-163.

${ }^{20}$ I thank the anonymous referee of the journal for pressing me to further clarify the idea of thin conception of the good.
} 
program based on their views could be problematic. This is partly why their proposal for compulsory moral bioenhancement focuses on three of the least controversial and the most essential moral dispositions: altruism, empathy, and a sense of justice. ${ }^{21}$ Persson and Savulescu's strategy shares the spirit of the capability approach I introduce here - focusing on the essentials and minimising required value commitments. In this respect, we should appreciate Persson and Savulescu's effort in arguing for the introduction of compulsory moral bioenhancement.

However, when we turn to the issue of how to conduct moral bioenhancement, we find that Persson and Savulescu's proposal unfortunately invites back certain thicker understandings of the related moral values. Take altruism as an example. Altruism as a broad moral concept can indeed be seen in most moral theories and would be consistent with most people's conceptions of the good. However, whether the biomedical means the authors suggest could remain open to various conceptions of the good is not entirely clear. For instance, during the discussion about the possibility of promoting altruism by using pharmaceuticals to increase the level of oxytocin in human body, Persson and Savulescu have noted that the type of altruism promoted in this way is better characterised as 'in-group altruism', i.e. altruism that only applies to individuals who are considered 'in-group members' ${ }^{22}$

Viewing this result from the lens of the capability approach, we may doubt that whether this sort of altruism is thin enough to be promoted in a liberal democratic society because this sort of altruism is deeply at odds with other potential interpretation of altruism. It would not,

\footnotetext{
21 See Persson and Savulescu 2012 op cit. note 4, pp. 123-124. Another two vital reasons for Persson and Savulescu to limit their proposal for a moral bioenhancement program to these three dispositions are (1) they believe these three dispositions are at the core of human morality and (2) there are numerous scientific studies suggesting that these three dispositions have biological roots and it is therefore possible to use biological means to enhance these dispositions. See Persson and Savulescu 2012 op cit. note 4, pp. 108-111.

${ }^{22}$ De Dreu, C. K. W., Greer, L. L., Handgraaf, M. J. J., Shalvi, S., Van Kleef, G. A., Baas, M., . . Feith, S. W. W. (2010). The neuropeptide oxytocin regulates parochial altruism in intergroup conflict among humans. Science, 328, 1408 - 1411. De Dreu, C. K. W., Greer, L. L., Van Kleef, G. A., Shalvi, S., \& Handgraaf, M. J. J. (2011). Oxytocin promotes human ethnocentrism. Proceedings of the National Academy of Sciences, 108(4), 1262-1266.
} 
for instance, work congruently with effective altruism, ${ }^{23}$ an influential interpretation of altruism which values impartiality greatly.

Furthermore, even if we agree that altruism, empathy, and a sense of justice are three of the fundamental values in human morality, how to prioritise these values may still create disagreement. We may follow Persson and Savulescu and agree that part of the reason that we fail to make significant progress on curbing climate change is due to our lack of altruistic motivation to help people who are severely affected by the changing climate. But there's another way to interpret our 'lack of altruism', i.e. we prioritise other values. Say, if we prioritise value of the rule of law, we'd have to respect the due process of legislation, and hence the slow progress in legislating new laws to address global climate change is a necessary evil. This is why while Persson and Savulescu could use capability approach to argue that developing these three values is vital for all sorts of human flourishment, this argument is not strong enough to provide a further defence for 'prioritising' these three values above other potentially equally important values. Arguing that we must prioritise values such as altruism, then, might be problematic.

This capability-approach-based critique, however, does not suggest that we ought to reject all moral bioenhancement programs. If a state-driven moral bioenhancement did not intend to prioritise any thicker values but instead focused on how to promote the essential capabilities that would ensure further development of any of these values, that sort of program could work consistently with the insights of the capability approach. ${ }^{24}$

Similar is the case of genuine moral education. Cautious readers may have noticed that education might encounter a similar problem when an educator tries to educate their students to value altruism and other fundamental moral values. An educator cannot begin teaching without using any concrete references that might implicitly endorse certain interpretations of the

${ }^{23}$ Singer, P. (1972). Famine, affluence, and morality. Philosophy and Public Affairs, 1(3), 229-243.

24 Cf. Schaefer, G. O., Kahane, G., \& Savulescu, J. (2014). Autonomy and enhancement. Neuroethics, 7(2), 123136; Schaefer, G. O., \& Savulescu, J. (2019). Procedural moral enhancement. Neuroethics, 12(1), 73-84 
values being discussed. Telling students the story of the good Samaritan, for instance, requires the educator to spend at least some time explaining the relationship between Samaritans, Levites, and Jews. Some might argue that such a brief introduction could be sufficient enough to cultivate an affinity with a Christian conception of the good, especially if this brief introduction interpreted the value of altruism with a thick Christian conception of the good. As a result, one might think that there's not much difference between moral education and the sort of statedriven moral bioenhancement advocated by Persson and Savulescu.

I think the concern that education could inculcate particular thick conceptions of the good is a fair one, which was partly why I mentioned earlier in this paper that education could become a tool for brainwashing. Indeed, teaching moral values almost always requires us to put these values in a certain context which risks 'instilling' the student with a rather thick conception of the good. Yet, again this sort of concern does not suggest 'genuine education' cannot exist.

In this respect, Sparrow is correct in introducing Jürgen Habermas's idea of the revisionary learning process when he's developing his argument against stat-driven moral bioenhancement. ${ }^{25}$ The Habermasian account distinguishes two types of 'fates' created by external influences: the socialisation fate and the natural fate. According to this account, although we are all ultimately 'fated' by our upbringing and genetic endowments, the moral implications of using social means to 'shape' others (socialisation fate) nevertheless differ greatly from the use of biological means (natural fate). The crux of this account lies in revisibility. ${ }^{26}$

According to Habermas, as children, we unavoidably go through a period where we must depend on our close family members. During this period, we are passively influenced by whatever they inculcate in us. It is in this sense that we are 'fated' by our socialisation. However,

${ }^{25}$ Habermas, J. (1987). The theory of communicative action, vol. 2, lifeworld and system: A critique of functionalist reason (T. McCarthy, Trans. Vol. 2); Habermas, J. (2003). The future of human nature. UK: Polity Press.

${ }^{26}$ I recently advanced a similar argument based on the feminist approach to autonomy. See Huang op cit. note 12. 
this 'fate' and the inequality between adults and young children in this scenario should not be viewed as inherently problematic because we can 'revise' the marks these social influences leave on our minds. It's like joining an existing dialogue. We need to listen to others first to get the context before we can actively contribute to dialogue. But once we have sufficient information, we may attempt to redirect the dialogue in a new direction as we wish. Conversely, natural fate usually leaves little room for revision. This is why Habermas argues strongly against using biotechnology to design the next generation - those who are 'programmed' might not be able, at some point in the future, to revise the ideals imposed by 'the programmers' ${ }^{27}$

Following Habermas's view, we may argue that while we almost always begin our moral education with a particular interpretation (hence, bringing a 'thick' interpretation of the value), well-designed moral education will ensure there's sufficient room for the educated to revise what they learn. For instance, after presenting the story of the Good Samaritan, the educator may also introduce other stories about altruism from different cultures to help their students understand that the purpose of this moral education is not to instil a particular thicker interpretation of altruism, but to use various references to cultivate the students' ability to reflect upon what they understand altruism to be and motivate them to develop their own conceptions of altruism. $^{28}$

\section{Conclusion}

Both state-driven moral bioenhancement and state-driven moral education contain pre-existing moral commitments, which shape, to some extent, the state's interactions with its citizens. This makes the anti-perfectionist argument against moral bioenhancement programs less convincing; this is especially so when one wants to use the same argument to support moral education.

\footnotetext{
27 Habermas 2003 op cit. note 24, pp 60-66.

28 I thank the anonymous referee of the journal for pressing me to clarify this point.
} 
After all, proponents of moral bioenhancement programs could simply point out the hidden commitments in the design of moral education and reply that even the least concerning attempt to improve others' morality are perfectionist. This is why I argue that the root of many people's discomfort with the idea of moral bioenhancement program lies elsewhere - in the moral commitments entailed by proposed programs. To evaluate the acceptability of a proposed moral bioenhancement program, we need to consider what moral commitments the enhancement program carries. For liberals who prioritise moral equality, the answer may be that the conception of the good hiding behind current proposals for moral bioenhancement is not thin enough. ${ }^{29}$

${ }^{29}$ I thank Robert Simpson for his generous support and invaluable feedback during the drafting of this paper. I also want to thank Toby Handfield, Justin Oakley, Lucy Valenta, two anonymous referees for Bioethics, and the participants of 2017 Annual Conference of Australasian Association of Philosophy at the University of Adelaide, Neuroscience and Society 2018 at Sydney, for providing me with helpful comments on earlier version of this articles. 